\title{
The Distribution of Zeroes and Critical Points of Solutions of a Second Order Half-Linear Differential Equation
}

\author{
Pedro Almenar ${ }^{1}$ and Lucas Jódar ${ }^{2}$ \\ ${ }^{1}$ Division of Network, Vodafone Spain, S.A., P. E. Castellana Norte, 28050 Madrid, Spain \\ ${ }^{2}$ Instituto Universitario de Matemática Multidisciplinar, Universitat Politècnica de València, Camino de Vera s/n, \\ 46022 Valencia, Spain
}

Correspondence should be addressed to Lucas Jódar; ljodar@imm.upv.es

Received 31 December 2012; Accepted 18 April 2013

Academic Editor: Elena Braverman

Copyright (C) 2013 P. Almenar and L. Jódar. This is an open access article distributed under the Creative Commons Attribution License, which permits unrestricted use, distribution, and reproduction in any medium, provided the original work is properly cited.

This paper reuses an idea first devised by Kwong to obtain upper bounds for the distance between a zero and an adjacent critical point of a solution of the second order half-linear differential equation $\left(p(x) \Phi\left(y^{\prime}\right)\right)^{\prime}+q(x) \Phi(y)=0$, with $p(x), q(x)>0, \Phi(t)=|t|^{r-2} t$, and $r$ real such that $r>1$. It also compares it with other methods developed by the authors.

\section{Introduction}

In a paper dated in 1981 (see [1]), Kwong suggested an idea to calculate Lyapunov inequalities for solutions of the second order linear differential equation as follows:

$$
y^{\prime \prime}+q(x) y=0, \quad x>x_{0},
$$

for the case $q(x)>0$, which was based in the concave nature of the solution $y(x)$. Years later, in [2], among many other interesting results, he applied such an idea to the determination of a sufficient condition for a solution of (1) to be oscillatory. Although the idea can also be employed to obtain upper bounds for the distance between zeroes and adjacent critical points of these solutions, seemingly Kwong did not get to elaborate it in that way (although very little effort had been needed to do it from the proof of Theorem 7 of [2] indeed), as a detailed analysis of his works shows (see [3] for a list of such works and links to the actual papers). Likewise, no other authors seem to have rediscovered it and used in the mentioned problem, to the knowledge of the authors.

Bearing that in mind, the purpose of this paper is to apply such an idea to the determination of upper bounds for the distance between zeroes and adjacent critical points of the solutions of the more general half-linear differential equation

$$
\left(p(x) \Phi\left(y^{\prime}\right)\right)^{\prime}+q(x) \Phi(y)=0, \quad x>x_{0}
$$

where $p(x), q(x)>0, \Phi(t)=|t|^{r-2} t$ and $r$ is a real number such that $r>1$, of which (1) is a very particular case.

The analysis of the maximum distance between zeroes and critical points is a problem which has received little or no attention in the last decades, apart from the paper [4], where the authors used Prüfer transformation techniques to elaborate two possible methods to tackle that problem. The reason for such little interest is unclear, anyway, given the success that its sibling problem (the determination of lower bounds or Lyapunov inequalities) has enjoyed in recent years (see [5-11]). As this paper will show, the method explained here improves those described in [4] in a significant amount of cases.

The organization of the paper is as follows. Section 2 will prove the main results and Section 3 will apply them in several examples so as to compare them with other methods from the authors. Finally Section 4 will state several conclusions. 


\section{Main Results}

We will start our analysis on the equation

$$
\left(\Phi\left(y^{\prime}\right)\right)^{\prime}+q(x) \Phi(y)=0, \quad x>x_{0}
$$

where $q(x)>0, \Phi(t)=|t|^{r-2} t$ and $r$ is a real number such that $r>1$, and we will extend it later to the more general equation (2).

Thus, let us prove the following lemma first.

Lemma 1. Let $y(x)$ be a solution of (3) with $q(x)$ piecewise continuous and positive on an interval I $\subset \mathfrak{R}$. In those intervals where $y(x)>0, y(x)$ is concave, and in those intervals where $y(x)<0, y(x)$ is convex.

Proof. From the definition of $\Phi(x)$, that is,

$$
\Phi(t)=|t|^{r-2} t
$$

it is straightforward to show that

$$
\left(\Phi\left(y^{\prime}\right)\right)^{\prime}=(r-1)\left|y^{\prime}\right|^{r-2} y^{\prime \prime} .
$$

Combining (3), (4), and (5) one has

$$
(r-1)\left|y^{\prime}\right|^{r-2} y^{\prime \prime}=-q(x)|y|^{r-2} y
$$

which implies that $y^{\prime \prime}$ has an opposite sign to that of $y$ and completes the proof. theorem

With the aid of Lemma 1 it is possible to prove the next

Theorem 2. Let $y(x)$ be a solution of (3) with $q(x)$ piecewise continuous and positive on an interval $I \subset \Re$. Let $a, b, a^{\prime}$, and $b^{\prime}$ be real numbers such that $[a, b] \subset I$ and $a \leq a^{\prime} \leq b^{\prime} \leq b$.

Then, if $y(a)=y^{\prime}(b)=0$ one has

$$
\int_{a^{\prime}}^{b^{\prime}} \sqrt[r-1]{\int_{x}^{b^{\prime}} q(s)\left(s-a^{\prime}\right)^{r-1} d s} d x \leq b^{\prime}-a^{\prime} .
$$

If $y^{\prime}(a)=y(b)=0$ one has

$$
\int_{a^{\prime}}^{b^{\prime}} \sqrt[r-1]{\int_{a^{\prime}}^{x} q(s)\left(b^{\prime}-s\right)^{r-1} d s} d x \leq b^{\prime}-a^{\prime}
$$

Proof. Let us focus first on proving (7). For the sake of simplicity let us assume that $y(x)>0$ on $] a, b]$ (the case $y(x)<0$ can be treated in the same manner).

From Lemma 1 it is clear that $y(x)$ must be concave and growing on $] a^{\prime}, b^{\prime}[$, which implies that

$$
y(s) \geq y\left(a^{\prime}\right)+\left(y\left(b^{\prime}\right)-y\left(a^{\prime}\right)\right) \frac{s-a^{\prime}}{b^{\prime}-a^{\prime}}, \quad s \in\left[a^{\prime}, b^{\prime}\right],
$$

that is,

$$
\begin{array}{r}
\Phi(y(s)) \geq\left[y\left(a^{\prime}\right)+\left(y\left(b^{\prime}\right)-y\left(a^{\prime}\right)\right) \frac{s-a^{\prime}}{b^{\prime}-a^{\prime}}\right]^{r-1}, \\
s \in\left[a^{\prime}, b^{\prime}\right] .
\end{array}
$$

If we apply (10) to (3) one yields

$$
\begin{array}{r}
\left(\Phi\left(y^{\prime}(s)\right)\right)^{\prime} \leq-q(s)\left[y\left(a^{\prime}\right)+\left(y\left(b^{\prime}\right)-y\left(a^{\prime}\right)\right) \frac{s-a^{\prime}}{b^{\prime}-a^{\prime}}\right]^{r-1}, \\
s \in\left[a^{\prime}, b^{\prime}\right] .
\end{array}
$$

Integrating (11) from $x$ to $b^{\prime}$ one gets

$$
\begin{aligned}
& \Phi\left(y^{\prime}(x)\right)-\Phi\left(y^{\prime}\left(b^{\prime}\right)\right) \\
& \geq \int_{x}^{b^{\prime}} q(s)\left[y\left(a^{\prime}\right)+\left(y\left(b^{\prime}\right)-y\left(a^{\prime}\right)\right) \frac{s-a^{\prime}}{b^{\prime}-a^{\prime}}\right]^{r-1} d s, \\
& x \in\left[a^{\prime}, b^{\prime}\right],
\end{aligned}
$$

that is,

$y^{\prime}(x)$

$$
\begin{array}{r}
\geq \sqrt[r-1]{\Phi\left(y^{\prime}\left(b^{\prime}\right)\right)+\int_{x}^{b^{\prime}} q(s)\left[y\left(a^{\prime}\right)+\left(y\left(b^{\prime}\right)-y\left(a^{\prime}\right)\right) \frac{s-a^{\prime}}{b^{\prime}-a^{\prime}}\right]^{r-1} d s} \\
x \in\left[a^{\prime}, b^{\prime}\right] .
\end{array}
$$

Integrating again (13) from $a^{\prime}$ to $b^{\prime}$ one yields

$$
\begin{aligned}
y\left(b^{\prime}\right) & \geq y\left(b^{\prime}\right)-y\left(a^{\prime}\right) \\
& \geq \int_{a^{\prime}}^{b^{\prime}} \sqrt[r-1]{\Phi\left(y^{\prime}\left(b^{\prime}\right)\right)+\int_{x}^{b^{\prime}} q(s)\left[y\left(a^{\prime}\right)+\left(y\left(b^{\prime}\right)-y\left(a^{\prime}\right)\right) \frac{s-a^{\prime}}{b^{\prime}-a^{\prime}}\right]^{r-1} d s d x} \\
& \geq \int_{a^{\prime}}^{b^{\prime}} \sqrt[r-1]{\int_{x}^{b^{\prime}} q(s) \frac{y^{r-1}\left(b^{\prime}\right)}{\left(b^{\prime}-a^{\prime}\right)^{r-1}}\left(s-a^{\prime}\right)^{r-1} d s d x,}
\end{aligned}
$$


given the linear character of $y\left(a^{\prime}\right)+\left(y\left(b^{\prime}\right)-y\left(a^{\prime}\right)\right)\left(\left(s-a^{\prime}\right) /\left(b^{\prime}-\right.\right.$ $\left.a^{\prime}\right)$ ) and the fact that $y(x), y^{\prime}(x) \geq 0$ on $[a, b]$. Equation (14) gives (7).

Let us focus now on (8). Again, for the sake of simplicity we will only consider the case $y(x) \geq 0$ on $[a, b]$.

From the concavity of $y(x)$ (Lemma 1$)$ one has

$$
y(s) \geq y\left(b^{\prime}\right)+\frac{y\left(a^{\prime}\right)-y\left(b^{\prime}\right)}{b^{\prime}-a^{\prime}}\left(b^{\prime}-s\right), \quad s \in\left[a^{\prime}, b^{\prime}\right],
$$

that is,

$$
\begin{array}{r}
\Phi(y(s)) \geq\left[y\left(b^{\prime}\right)+\frac{y\left(a^{\prime}\right)-y\left(b^{\prime}\right)}{b^{\prime}-a^{\prime}}\left(b^{\prime}-s\right)\right]^{r-1}, \\
s \in\left[a^{\prime}, b^{\prime}\right] .
\end{array}
$$

If we apply (16) to (3) one yields

$$
\begin{array}{r}
\left(\Phi\left(y^{\prime}(s)\right)\right)^{\prime} \leq-q(s)\left[y\left(b^{\prime}\right)+\frac{y\left(a^{\prime}\right)-y\left(b^{\prime}\right)}{b^{\prime}-a^{\prime}}\left(b^{\prime}-s\right)\right]^{r-1}, \\
s \in\left[a^{\prime}, b^{\prime}\right] .
\end{array}
$$

Integrating (17) from $a^{\prime}$ to $x$ one gets

$$
\begin{aligned}
& \Phi\left(y^{\prime}(x)\right) \\
& \leq \Phi\left(y^{\prime}(a)\right)-\int_{a^{\prime}}^{x} q(s)\left[y\left(b^{\prime}\right)+\frac{y\left(a^{\prime}\right)-y\left(b^{\prime}\right)}{b^{\prime}-a^{\prime}}\left(b^{\prime}-s\right)\right]^{r-1} d s, \\
& x \in\left[a^{\prime}, b^{\prime}\right],
\end{aligned}
$$

that is,

$$
\begin{aligned}
& y^{\prime}(x) \\
& \leq-\sqrt[r-1]{-\Phi\left(y^{\prime}(a)\right)+\int_{a^{\prime}}^{x} q(s)\left[y\left(b^{\prime}\right)+\frac{y\left(a^{\prime}\right)-y\left(b^{\prime}\right)}{b^{\prime}-a^{\prime}}\left(b^{\prime}-s\right)\right]^{r-1} d s,} \\
& x \in\left[a^{\prime}, b^{\prime}\right] .
\end{aligned}
$$

Integrating again (19) from $a^{\prime}$ to $b^{\prime}$ one yields

$$
\begin{aligned}
y\left(a^{\prime}\right) & \geq y\left(a^{\prime}\right)-y\left(b^{\prime}\right) \\
& \geq \int_{a^{\prime}}^{b^{\prime}} \sqrt[r-1]{-\Phi\left(y^{\prime}(a)\right)+\int_{a^{\prime}}^{x} q(s)\left[y\left(b^{\prime}\right)+\frac{y\left(a^{\prime}\right)-y\left(b^{\prime}\right)}{b^{\prime}-a^{\prime}}\left(b^{\prime}-s\right)\right]^{r-1} d s d x} \\
& \geq \int_{a^{\prime}}^{b^{\prime}} \sqrt[r-1]{\int_{a^{\prime}}^{x} q(s)\left[\frac{y\left(a^{\prime}\right)}{b^{\prime}-a^{\prime}}\left(b^{\prime}-s\right)\right]^{r-1}} d s d x,
\end{aligned}
$$

given that $y(x) \geq 0$ and $y^{\prime}(x) \leq 0$ on $[a, b]$ and the linear character of $y\left(b^{\prime}\right)+\left(\left(y\left(a^{\prime}\right)-y\left(b^{\prime}\right)\right) /\left(b^{\prime}-a^{\prime}\right)\right)\left(b^{\prime}-s\right)$. Equation (20) gives (8).

Remark 3. From Theorem 2 it becomes clear that, fixed $a^{\prime}=$ $a$, any value of the extreme $b^{\prime}$ that violates either (7) or (8), depending on the case, will be an upper bound for the zero or critical point $b$, given that all values of $b^{\prime}$ between $a$ and $b$ must satisfy such formulae. Likewise, if we fix $b^{\prime}=b$, any value of the extreme $a^{\prime}$ that violates either (7) or (8), depending on the case, will be a lower bound for the zero or critical point $a^{\prime}$. However, it is important to remark that there is no guarantee that an extreme that violates either (7) or (8), depending on the case, can be found in all cases, as one of the examples of Section 3 will show.

For the particular linear case $r=2$ it is possible to obtain the following corollary.

Corollary 4. Let $y(x)$ be a solution of (1) with $q(x)$ piecewise continuous and positive on an interval $I \subset \Re$. Let $a, b, a^{\prime}$, and $b^{\prime}$ be real numbers such that $[a, b] \subset I$ and $a \leq a^{\prime} \leq b^{\prime} \leq b$.
Then, if $y(a)=y^{\prime}(b)=0$ one has

$$
\int_{a^{\prime}}^{b^{\prime}} q(x)\left(x-a^{\prime}\right)^{2} d x \leq b^{\prime}-a^{\prime} .
$$

If $y^{\prime}(a)=y(b)=0$ one has

$$
\int_{a^{\prime}}^{b^{\prime}} q(x)\left(b^{\prime}-x\right)^{2} d x \leq b^{\prime}-a^{\prime} .
$$

Proof. Let us focus first on proving (21). Setting $r=2$ (the linear case) in (7) one gets

$$
\int_{a^{\prime}}^{b^{\prime}} \int_{x}^{b^{\prime}} q(s)\left(s-a^{\prime}\right) d s d x \leq b^{\prime}-a^{\prime} .
$$

Integrating by parts (23) one gets (21). The proof of (22) is similar and will not be repeated.

Remark 5. Equation (21), in fact, was obtained by Kwong as an intermediate result in the proof of [2, Theorem 7], focused on the determination of the oscillatory nature of a solution of (1). 
Corollary 4 allows to tackle the problem of getting upper bounds for the distance between consecutive zeroes of the solution of (1), as the next corollary shows.

Corollary 6. Let $y(x)$ be a solution of (1) with $q(x)$ piecewise continuous and positive on an interval $I \subset \mathfrak{R}$. Let $a, b$ be adjacent zeroes of $y(x)$ such that $[a, b] \subset I$ and let $a^{\prime}, b^{\prime}$ be such that $a \leq a^{\prime} \leq b^{\prime} \leq b$.

If we define $S(x)$ as the function

$$
S(x)= \begin{cases}\left(x-a^{\prime}\right)^{2}, & x \in\left[a^{\prime}, \frac{b^{\prime}+a^{\prime}}{2}\right], \\ \left(b^{\prime}-x\right)^{2}, & x \in\left[\frac{b^{\prime}+a^{\prime}}{2}, b^{\prime}\right],\end{cases}
$$

then one has

$$
\int_{a^{\prime}}^{b^{\prime}} q(x) S(x) d x \leq b^{\prime}-a^{\prime} .
$$

Proof. If $a, b$ are consecutive zeroes of $y(x)$, by Rolle's theorem there must exist a point $c \in] a, b\left[\right.$, such that $y^{\prime}(c)=0$.

If $\left[a^{\prime}, b^{\prime}\right] \subset[a, c]$ then (25) results from (21) and the fact that $S(x) \leq\left(x-a^{\prime}\right)^{2}$. Likewise, if $\left[a^{\prime}, b^{\prime}\right] \subset[c, b]$ then (25) results from (22) and the fact that $S(x) \leq\left(b^{\prime}-x\right)^{2}$.

On the contrary, if $c \in\left[a^{\prime}, b^{\prime}\right]$, then we can apply Corollary 4 to yield

$$
\begin{gathered}
\int_{a^{\prime}}^{c} q(x)\left(x-a^{\prime}\right)^{2} d x+\int_{c}^{b^{\prime}} q(x)\left(b^{\prime}-x\right)^{2} d x \\
\leq c-a^{\prime}+b^{\prime}-c=b^{\prime}-a^{\prime} .
\end{gathered}
$$

If we minimize the left hand side of (26) on $c$, it is easy to prove that the minimum occurs at $c=\left(b^{\prime}+a^{\prime}\right) / 2$. Setting such a value of $c$ on (26) and taking into account the definition of $S(x)$, one gets (25).

Remark 7. For the same reasons as before, fixed $a^{\prime}=a$, any value of the extreme $b^{\prime}$ that violates (26) will be an upper bound for the value of the zero $b$, and fixed $b^{\prime}=b$, any value of the extreme $a^{\prime}$ that violates (26) will be a lower bound for the value of the zero $a$. In general, for any values $a^{\prime}, b^{\prime}$ that violate (26) there must be at least one zero $b$ of the solution of (1) such that $b \in] a^{\prime}, b^{\prime}[$.

Now we can turn our eyes into the more general equation (2), which we will do in the next theorem.

Theorem 8. Let $y(x)$ be a solution of (2) with $p(x), q(x)$ piecewise continuous and positive on an interval $I \subset \Re$. Let $a, b, a^{\prime}$, and $b^{\prime}$ be real numbers such that $[a, b] \subset I$ and $a \leq a^{\prime} \leq b^{\prime} \leq b$.

Then, if $y(a)=y^{\prime}(b)=0$ one has

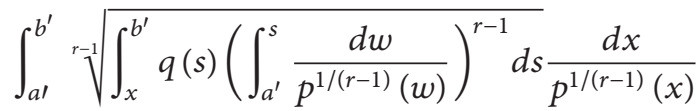

$$
\begin{aligned}
& \leq \int_{a^{\prime}}^{b^{\prime}} \frac{d x}{p^{1 /(r-1)}(x)} . \\
& \text { If } y^{\prime}(a)=y(b)=0 \text { one has }
\end{aligned}
$$

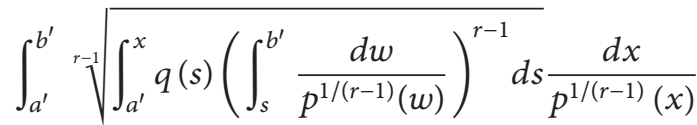

$$
\begin{aligned}
& \leq \int_{a^{\prime}}^{b^{\prime}} \frac{d x}{p^{1 /(r-1)}(x)} .
\end{aligned}
$$

Proof. Let us focus first on proving (27). By the change of variables

$$
u=\varphi(x)=\int_{0}^{x} \frac{d t}{p^{1 /(r-1)}(t)},
$$

which maps the interval $[a, b]$ onto $[\varphi(a), \varphi(b)]$, it is possible (see [5]) to convert (2) into the equation

$$
\frac{d}{d u}\left(\Phi\left(\frac{d y}{d u}\right)\right)+p^{1 /(r-1)}\left(\varphi^{-1}(u)\right) q\left(\varphi^{-1}(u)\right) \Phi(y(u))=0 .
$$

From the derivative of the inverse function one yields

$$
\frac{d y}{d u}(\varphi(b))=y^{\prime}(b)\left(\varphi^{-1}\right)^{\prime}(\varphi(b))=y^{\prime}(b) p^{1 /(r-1)}(b),
$$

which makes clear that $(d y / d u)(\varphi(b))=0$ if and only if $y^{\prime}(b)=0$.

Then, given that $y(\varphi(a))=(d y / d u)(\varphi(b))=0$, we can apply Theorem 2 to $(30)$ on the interval $[\varphi(a), \varphi(b)]$ to yield

$$
\begin{gathered}
\int_{\varphi\left(a^{\prime}\right)}^{\varphi\left(b^{\prime}\right)} \sqrt[r-1]{\int_{z}^{\varphi\left(b^{\prime}\right)} p^{1 /(r-1)}\left(\varphi^{-1}(u)\right) q\left(\varphi^{-1}(u)\right)\left(u-\varphi\left(a^{\prime}\right)\right)^{r-1} d u} d z \\
\quad \leq \varphi\left(b^{\prime}\right)-\varphi\left(a^{\prime}\right)=\int_{a^{\prime}}^{b^{\prime}} \frac{d x}{p^{1 /(r-1)}(x)} .
\end{gathered}
$$

Making the change of variable $x=\varphi^{-1}(z)$ in (32) and using (29) one gets

$$
\begin{aligned}
\int_{a^{\prime}}^{b^{\prime}} & \sqrt[r-1]{\int_{\varphi(x)}^{\varphi\left(b^{\prime}\right)} p^{1 /(r-1)}\left(\varphi^{-1}(u)\right) q\left(\varphi^{-1}(u)\right)\left(u-\varphi\left(a^{\prime}\right)\right)^{r-1} d u} \frac{d x}{p^{1 /(r-1)}(x)} \\
& \leq \int_{a^{\prime}}^{b^{\prime}} \frac{d x}{p^{1 /(r-1)}(x)} .
\end{aligned}
$$


Making a new change of variable $s=\varphi^{-1}(u)$ in (32) one gets (27).

The proof of (28) is very similar and will not be repeated.

As happened before, for the particular linear case $r=2$ it is possible to obtain the following corollaries.

Corollary 9. Let $y(x)$ be a solution of (2) with $r=2$ and $p(x)$, $q(x)$ piecewise continuous and positive on an interval $I \subset \Re$. Let $a, b, a^{\prime}$, and $b^{\prime}$ be real numbers such that $[a, b] \subset I$ and $a \leq a^{\prime} \leq b^{\prime} \leq b$.

Then, if $y(a)=y^{\prime}(b)=0$ one has

$$
\int_{a^{\prime}}^{b^{\prime}} q(x)\left(\int_{a^{\prime}}^{x} \frac{d t}{p(t)}\right)^{2} d s \leq \int_{a^{\prime}}^{b^{\prime}} \frac{d x}{p(x)} .
$$

If $y^{\prime}(a)=y(b)=0$ one has

$$
\int_{a^{\prime}}^{b^{\prime}} q(x)\left(\int_{x}^{b^{\prime}} \frac{d t}{p(t)}\right)^{2} d s \leq \int_{a^{\prime}}^{b^{\prime}} \frac{d x}{p(x)} .
$$

Proof. The proof can be done setting $r=2$ in (27)-(28) and integrating by parts.

Corollary 10. Let $y(x)$ be a solution of (2) with $r=2$ and $p(x), q(x)$ piecewise continuous and positive on an interval $I \subset$ $\mathfrak{R}$. Let $a, b$ be adjacent zeroes of $y(x)$ such that $[a, b] \subset I$ and let $a^{\prime}, b^{\prime}$ be such that $a \leq a^{\prime} \leq b^{\prime} \leq b$.

If we define $d$ as the point on $] a^{\prime}, b^{\prime}$ [ such that

$$
\int_{a^{\prime}}^{d} \frac{d x}{p(x)}=\int_{d}^{b^{\prime}} \frac{d x}{p(x)}
$$

and $S(x)$ as the function

$$
S(x)= \begin{cases}\left(\int_{a^{\prime}}^{x} \frac{d t}{p(t)}\right)^{2}, & x \in\left[a^{\prime}, d\right], \\ \left(\int_{x}^{b^{\prime}} \frac{d t}{p(t)}\right)^{2}, & x \in\left[d, b^{\prime}\right],\end{cases}
$$

then one has

$$
\int_{a^{\prime}}^{b^{\prime}} q(x) S(x) d x \leq \int_{a^{\prime}}^{b^{\prime}} \frac{d x}{p(x)} .
$$

Proof. The proof follows the same steps of that of Corollary 6 and will be omitted.

Remark 11. As happened before, for any values $a^{\prime}, b^{\prime}$ that violate (38) there must be at least one zero $b$ of the solution of (2) with $r=2$ such that $b \in] a^{\prime}, b^{\prime}[$.

\section{Some Examples}

\begin{tabular}{|c|c|c|c|c|}
\hline $\begin{array}{l}\text { Exponent } \\
r\end{array}$ & Case & Theorem 2 & $\begin{array}{c}{[4, \text { Corollary }} \\
2.6]\end{array}$ & $\begin{array}{c}\text { [4, Theorem } \\
3.1]\end{array}$ \\
\hline$r=1.5$ & $y(1)=y^{\prime}(b)=0$ & $b \leq 3.32$ & $b \leq 3.26$ & $b \leq 2.99$ \\
\hline$r=1.5$ & $y^{\prime}(1)=y(b)=0$ & $b \leq 2.97$ & $b \leq 2.86$ & $b \leq 2.99$ \\
\hline$r=5.0$ & $y(1)=y^{\prime}(b)=0$ & $b \leq 2.58$ & $b \leq 2.55$ & $b \leq 2.54$ \\
\hline$r=5.0$ & $y^{\prime}(1)=y(b)=0$ & $b \leq 2.47$ & $b \leq 2.49$ & $b \leq 2.54$ \\
\hline
\end{tabular}

Throughout this section we will introduce examples where upper bounds for the distance between a zero and an adjacent critical point of a solution of (2) will be provided by means
TABLE 1: Comparison of upper bounds for $b$ in Example 12.

TABLE 2: Comparison of upper bounds for $b$ in Example 13.

\begin{tabular}{llccc}
\hline $\begin{array}{l}\text { Exponent } \\
r\end{array}$ & \multirow{2}{*}{ Case } & \multirow{2}{*}{ Theorem 2 } & $\begin{array}{c}\text { [4, Corollary } \\
\text { 2.6 }\end{array}$ & $\begin{array}{c}\text { [4, Theorem } \\
\text { 3.1] }\end{array}$ \\
\hline$r=1.5$ & $y(1)=y^{\prime}(b)=0$ & $b \leq 2.16$ & $b \leq 2.14$ & $b \leq 2.20$ \\
$r=1.5$ & $y^{\prime}(1)=y(b)=0$ & $b \leq 2.35$ & $b \leq 2.53$ & $b \leq 2.20$ \\
$r=5.0$ & $y(1)=y^{\prime}(b)=0$ & $b \leq 2.25$ & $b \leq 2.28$ & $b \leq 2.37$ \\
$r=5.0$ & $y^{\prime}(1)=y(b)=0$ & $b \leq 2.40$ & $b \leq 2.42$ & $b \leq 2.37$ \\
\hline
\end{tabular}

TABLE 3: Comparison of upper bounds for $b$ in Example 14.

\begin{tabular}{llccc}
\hline $\begin{array}{l}\text { Exponent } \\
r\end{array}$ & Case & \multirow{2}{*}{ Theorem 8 } & $\begin{array}{c}\text { [4, Theorem } \\
\text { 2.3] }\end{array}$ & $\begin{array}{c}\text { [4, Theorem } \\
\text { 3.1] }\end{array}$ \\
\hline$r=1.5$ & $y(1)=y^{\prime}(b)=0$ & $b \leq 2.10$ & $b \leq 2.012$ & $b \leq 2.01$ \\
$r=1.5$ & $y^{\prime}(1)=y(b)=0$ & $b \leq 2.10$ & $b \leq 2.012$ & $b \leq 2.01$ \\
$r=5.0$ & $y(1)=y^{\prime}(b)=0$ & $b \leq 2.21$ & $b \leq 2.32$ & $b \leq 3.09$ \\
$r=5.0$ & $y^{\prime}(1)=y(b)=0$ & $b \leq 2.32$ & $b \leq 2.43$ & $b \leq 3.09$
\end{tabular}

TABLE 4: Comparison of upper bounds for $b$ in Example 15.

\begin{tabular}{llccc}
\hline $\begin{array}{l}\text { Exponent } \\
r\end{array}$ & Case & \multirow{2}{*}{ Theorem 8 } & $\begin{array}{c}\text { [4, Corollary } \\
\text { 2.6] }\end{array}$ & $\begin{array}{c}\text { [4, Theorem } \\
3.1]\end{array}$ \\
\hline$r=1.5$ & $y(1)=y^{\prime}(b)=0$ & $b \leq 1.13$ & $b \leq 1.325$ & $b \leq 1.33$ \\
$r=1.5$ & $y^{\prime}(1)=y(b)=0$ & No valid $b$ & No valid $b$ & $b \leq 1.33$ \\
$r=5.0$ & $y(1)=y^{\prime}(b)=0$ & $b \leq 1.28$ & $b \leq 1.39$ & $b \leq 1.83$ \\
$r=5.0$ & $y^{\prime}(1)=y(b)=0$ & $b \leq 1.68$ & $b \leq 2.19$ & $b \leq 1.83$ \\
\hline
\end{tabular}

of the methods described in Theorems 2 and 8 and other two methods introduced in [4, Theorems 2.3 and 3.1, and Corollary 2.6] for the same half-linear equation. All the examples will address the cases $r=1.5$ and $r=5$, to cope with half-linear equations whose exponent $r$ is lower and upper (resp.) than the value $r$ of the linear case $(r=2)$. To simplify the comparison, the analysis will fix the value of the starting point $a$ (either a zero or a critical point) and will search for an upper bound of the corresponding point $b$ (next critical point or zero, respectively, adjacent to $a$ ), and the used examples will be the same ones presented in [4].

Example 12. Let us consider the following half-linear differential equation:

$$
\Phi\left(y^{\prime}\right)^{\prime}+\frac{1}{\sqrt{x}} \Phi(y)=0, \quad x \geq 1, \quad a=1 .
$$

The application of Theorem 2 and [4, Corollary 2.6 and Theorem 3.1] to this example yields Table 1. 
As can be seen in Table 1 , in the case $y(1)=y^{\prime}(b)=0$ the bounds obtained using Theorem 2 do not improve any of the bounds obtained using [4, Corollary 2.6 and Theorem 3.1] for both values $r=1.5$ and $r=5$. However, in the case $y^{\prime}(1)=$ $y(b)=0$, the bound obtained using Theorem 2 is the best when $r=5$ and is the second best when $r=1.5$, being only improved by that of [4, Corollary 2.6].

Example 13. Let us consider the following half-linear differential equation:

$$
\Phi\left(y^{\prime}\right)^{\prime}+x \Phi(y)=0, \quad x \geq 1, \quad a=1 .
$$

The application of Theorem 2 and [4, Corollary 2.6 and Theorem 3.1] to this example yields Table 2 .

As can be seen in Table 2, in the case $y(1)=y^{\prime}(b)=0$ the bounds obtained using Theorem 2 improve all the bounds obtained using [4, Corollary 2.6 and Theorem 3.1] when $r=5$, and at least the bound coming from [4, Theorem 3.1] when $r=1.5$. In contrast, in the case $y^{\prime}(1)=y(b)=0$, the bounds obtained using Theorem 2 only improve those coming from [4, Corollary 2.6] for both $r=5$ and $r=1.5$, being improved by those of [4, Theorem 3.1] for both values of $r$.

Example 14. Let us consider the following half-linear differential equation:

$$
\left(\frac{1}{\sqrt{x}} \Phi\left(y^{\prime}\right)\right)^{\prime}+x \Phi(y)=0, \quad x \geq 1, \quad a=1 .
$$

The application of Theorem 8 and [4, Theorems 2.3 and 3.1] to this example yields Table 3 .

As can be seen in Table 3, when $r=5$ the bounds obtained using Theorem 8 are better than the bounds obtained using [4, Theorems 2.3 and 3.1] for both cases $y(1)=y^{\prime}(b)=0$ and $y^{\prime}(1)=y(b)=0$, being worse than these other bounds when $r=1.5$, again in both cases.

Example 15. Let us consider the following half-linear differential equation:

$$
\left(e^{x} \Phi\left(y^{\prime}\right)\right)^{\prime}+e^{x} \Phi(y)=0, \quad x \geq 0, \quad a=0 .
$$

The application of Theorem 8 and [4, Corollary 2.6 and Theorem 3.1] to this example yields Table 4 .

As can be seen in Table 4, the bounds obtained using Theorem 8 are better than the bounds obtained using [4, Corollary 2.6 and Theorem 3.1] in all cases, with the exception of the case $r=1.5, y^{\prime}(1)=y(b)=0$, where Theorem 8 does not allow to calculate any valid upper bound, a possibility already mentioned in Remark 3.

\section{Conclusions}

The method described in this paper provides upper bounds for the distance between the zeroes and their adjacent critical points of the solutions of the half-linear differential equations (2) and (3).

Its main interest comes from the fact that the amount of methods that address that problem as of today is quite small (in fact, to the knowledge of the authors, it is reduced to those presented in [4]).

When compared with the methods described in that reference, the one introduced in this paper yields bounds which are better in several cases (in Example 15, in fact in almost all cases) and worse in some others. It seems difficult to find a possible trend on which method is best for which case, but generally speaking it looks like higher values of the exponent $r$ favour this method, if we dare to extrapolate the results of the examples of the previous section.

The main limitations of this method are the same as those of [4, Theorem 2.3], that is, the need for $p(x), q(x)$ to be strictly positive on $[a, b]$ and the fact that this method does not allow to calculate a valid upper bound in some rare cases, which is something that does not happen with [4, Theorem 3.1].

\section{Acknowledgment}

This work has been supported by the Spanish Ministry of Science and Innovation Project DPI2010-C02-01.

\section{References}

[1] M. K. Kwong, "On Lyapunov's inequality for disfocality," Journal of Mathematical Analysis and Applications, vol. 83, no. 2, pp. 486-494, 1981.

[2] M. K. Kwong, "Integral inequalities for second-order linear oscillation," Mathematical Inequalities and Applications, vol. 2, no. 1, pp. 55-71, 1999.

[3] Online list of Kwong papers, http://myweb.polyu.edu.hk/ $\sim$ mankwong/pubs.html.

[4] P. Almenar and L. Jódar, "On the zeroes and the critical points of a solution of a second order half-linear differential equation," Abstract and Applied Analysis, vol. 2012, Article ID 787920, 18 pages, 2012.

[5] O. Došlý and P. Řehák, Half-Linear Differential Equations, vol. 202 of Mathematics Studies, North-Holland, 2005.

[6] Á. Elbert, "A half-linear second order differential equation," Colloquia Mathematica Societatis János Bolyai, vol. 30, pp. 158180, 1979.

[7] H. J. Li and C. C. Yeh, "Sturmian comparison theorem for halflinear second-order differential equations," Proceedings of the Royal Society of Edinburgh A, vol. 125, no. 6, pp. 1193-1204, 1995.

[8] X. Yang, "On inequalities of Lyapunov type," Applied Mathematics and Computation, vol. 134, no. 2-3, pp. 293-300, 2003.

[9] C.-F. Lee, C.-C. Yeh, C.-H. Hong, and R. P. Agarwal, "Lyapunov and Wirtinger inequalities," Applied Mathematics Letters, vol. 17, no. 7, pp. 847-853, 2004.

[10] J. P. Pinasco, "Lower bounds for eigenvalues of the onedimensional p-Laplacian," Abstract and Applied Analysis, vol. 2004, no. 2, pp. 147-153, 2004.

[11] J. P. Pinasco, "Comparison of eigenvalues for the $p$-Laplacian with integral inequalities," Applied Mathematics and Computation, vol. 182, no. 2, pp. 1399-1404, 2006. 


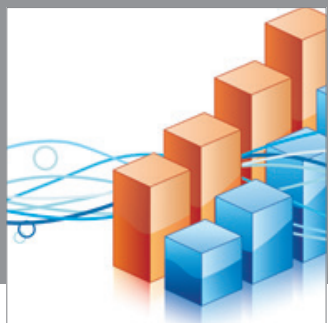

Advances in

Operations Research

mansans

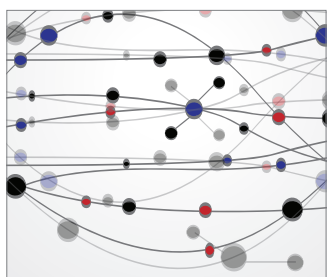

The Scientific World Journal
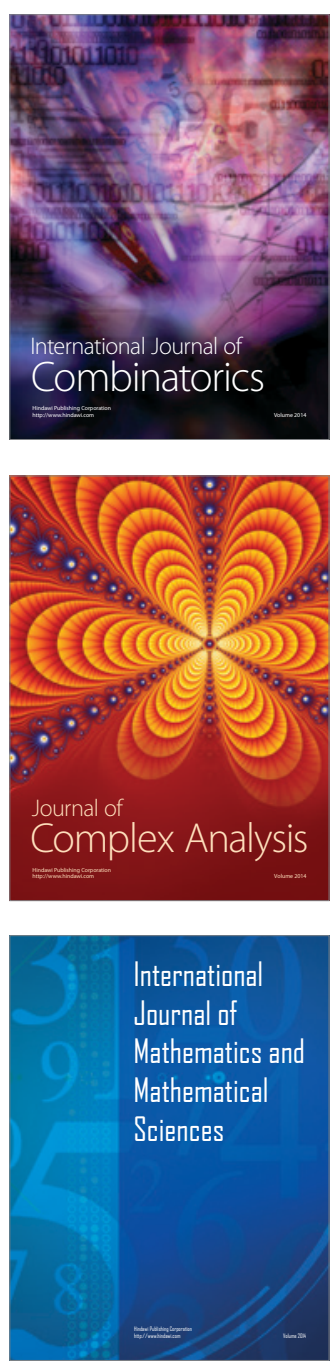
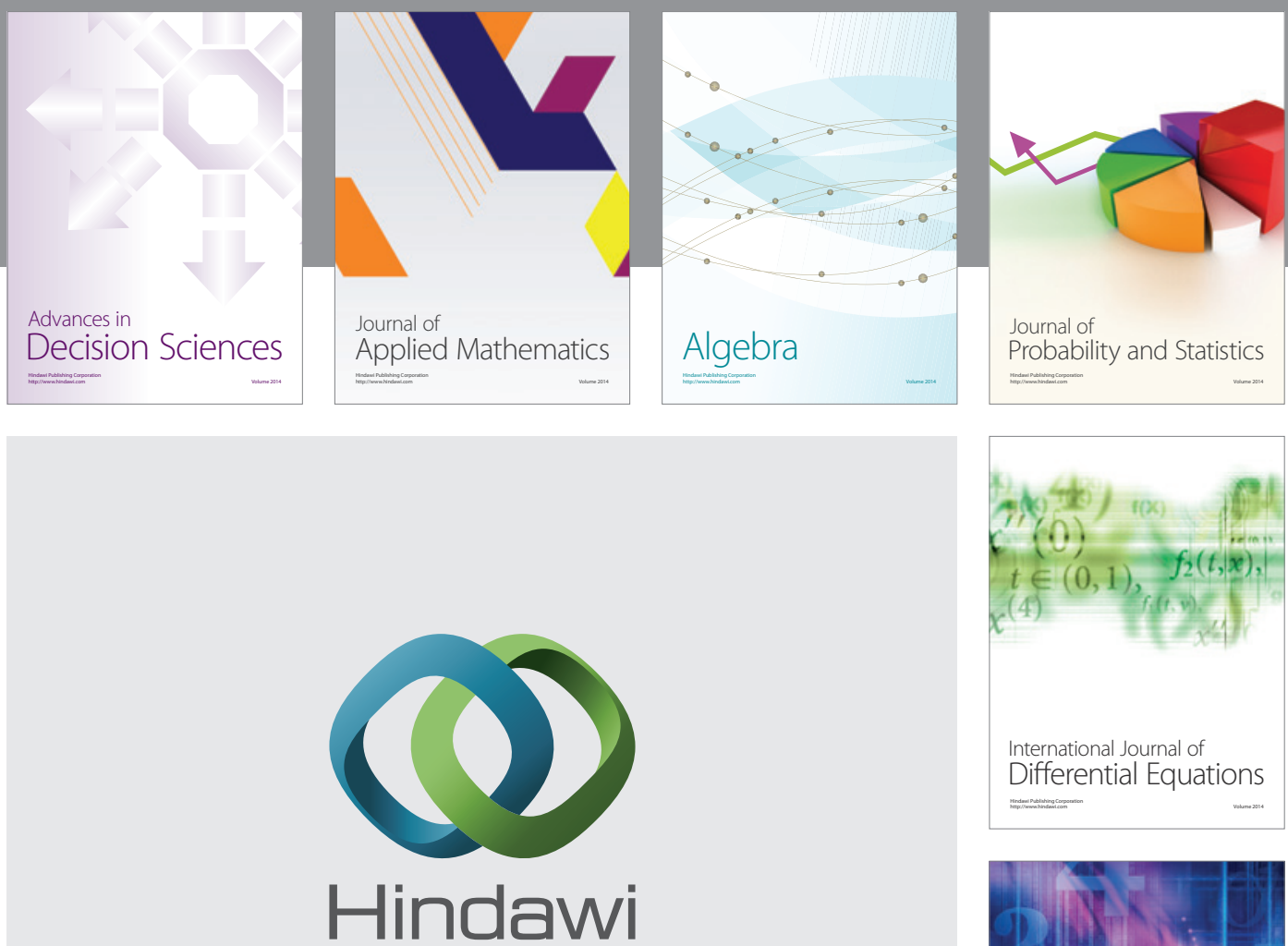

Submit your manuscripts at http://www.hindawi.com
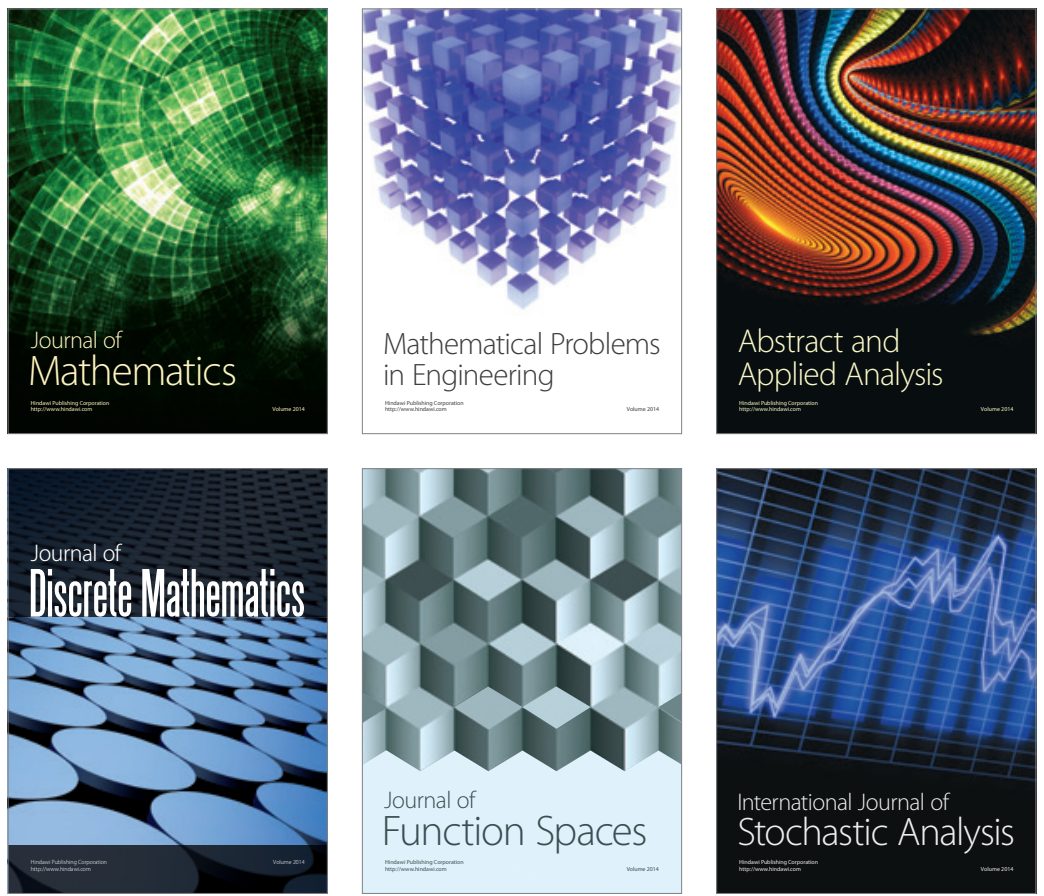

Journal of

Function Spaces

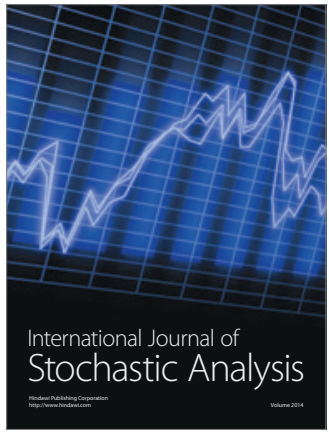

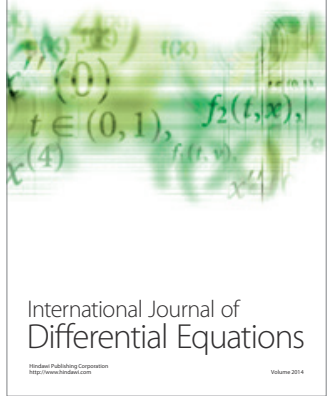
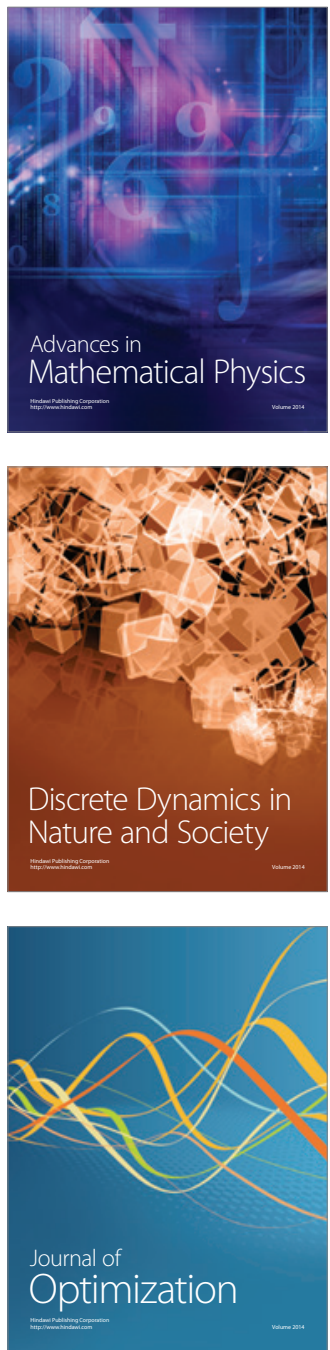